\title{
Precipitation of silica from zinc process solution
}

\section{Tuomas Vielma ${ }^{1} \bullet$ Ulla Lassi $^{2} \bullet$ Justin Salminen $^{3}$}

4 Received: .Accepted ...

7 Abstract Precipitation of silica during hot acid leach of zinc residue was

8 studied with laboratory-scale batch experiments. It was observed that the

9 high ionic strength of the leaching solution drastically decreases the

10 solubility of silica. The solubility was also studied by Gibbs energy

11 minimization method using the software ChemSheet. Good agreement was

12 obtained between the model and experimental results. The precipitation

13 reaction was observed to follow a pseudo-first order rate-law. Effects of

14 initial silicic acid concentration, temperature and sulfuric acid concentration

15 were studied. Based on the used rate-law, an activation energy of 61,7 kJ

$16 \mathrm{~mol}^{-1}$ was estimated, implying a reaction-controlled mechanism of

17 precipitation.

20 Keywords Kinetics $\bullet$ Thermodynamics $\bullet$ Zinc $\bullet$ Silica $\bullet$ Salt effect $\bullet$ 21 Solubility

$23 \bar{\square}$ Tuomas Vielma

24 tuomas.vielma@chydenius.fi

251 Tuomas Vielma, University of Oulu, Oulu, Finland 
12 Justin Salminen, affiliation of second author

23 Ulla Lassi, University of Oulu, Oulu, Finland

3 Introduction

4 Gelling of silicic acid is a widely-recognized problem in

5 hydrometallurgical recovery of zinc. Acid leaching of silicate minerals such

6 as willemite $\mathrm{Zn}_{2} \mathrm{SiO}_{4}(\mathrm{~s})$ and hemimorphite $\mathrm{Zn}_{4} \mathrm{Si}_{2} \mathrm{O}_{7}(\mathrm{OH})_{2} \cdot \mathrm{H}_{2} \mathrm{O}$ (s)

7 liberates various silicic acid species into the process solution [1], in

8 accordance with equations 1 and 2:

$$
\mathrm{Zn}_{2} \mathrm{SiO}_{4}(\mathrm{~s})+4 \mathrm{H}^{+}(\mathrm{aq}) \Leftrightarrow 2 \mathrm{Zn}^{2+}(\mathrm{aq})+\mathrm{Si}(\mathrm{OH})_{4}(\mathrm{aq})
$$

9

$$
\mathrm{Zn}_{4} \mathrm{Si}_{2} \mathrm{O}_{7}(\mathrm{OH})_{2} \cdot \mathrm{H}_{2} \mathrm{O}(\mathrm{s})+8 \mathrm{H}^{+}(\mathrm{aq}) \Leftrightarrow 4 \mathrm{Zn}^{2+}+\mathrm{Si}_{2} \mathrm{O}(\mathrm{OH})_{6}(\mathrm{aq})+3 \mathrm{H}_{2} \mathrm{O}
$$

10 At high concentrations polymerization and gelling of silicic acid can be

11 observed. This leads to difficulties with settling, filtering and washing of

12 the process solution and may even hinder the leaching process itself. Due

13 to its slow sedimentation velocity, silicic acid gel is practically impossible

14 to separate from the solution in a thickener. Formation of the gel can thus

15 hinder the operation of later stages, including hot acid leach and

16 electrowinning [1-6]. 
1 Due to its status as a global problem in hydrometallurgy of zinc, many

2 attempts have been made to control the precipitation and gelling of silicic

3 acid. Several patents have been issued for processes capable of processing

4 silica bearing raw material. The Radino process was one the earliest

5 attempts, later improved by Matthew and Elsner $[3,7,8]$. Key idea of the

6 process is to, after leaching of the raw material, neutralize the leaching

7 solution with $\mathrm{ZnO}$ to $\mathrm{pH}$ of 4-5 where colloidal silica is most unstable [9].

8 Temperature is maintained at $50-60{ }^{\circ} \mathrm{C}$ to prevent uncontrolled

9 precipitation of silica and loss of zinc. Precipitated silica is separated by

10 filtration. Aluminium sulfate is added to increase the rate of precipitation of

11 silica. Although the modified Radino process can handle high silica

12 concentrations, a sudden halt at the process can cause uncontrollable

13 gelling of silica with detrimental results for the whole process chain. To

14 tackle this problem, the Outokumpu process was developed [10].

15 Whereas the modified Radino process relied on multiple successive reactors,

16 Outokumpu process was developed for a single reactor. The process was

17 designed to precipitate silica at the same rate silica bearing material is

18 introduced to the process. High acid concentration, $20-100 \mathrm{~g} \mathrm{H}_{2} \mathrm{SO}_{4} \mathrm{dm}^{-3}$,

19 and high operation temperature, $70{ }^{\circ} \mathrm{C}$, are used to ensure complete

20 dissolution of silicates. By maintaining silica concentration at $0.5-2.0 \mathrm{~g}$

$21 \mathrm{SiO}_{2} \mathrm{dm}^{-3}$, easily filterable precipitate is obtained. Similar concentration 
1 limits have been found by other parties [11]. Clear advantages of Outokumpu

2 process are also the simplicity of the necessary facilities and their

3 operation [10].

4 As was pointed out by Cooper, processes designed to treat silicate-bearing

5 zinc concentrates were created when the knowledge of the solution behavior

6 and precipitation of silicic acid was still lacking [11]. In the systems

7 considered here, solubility of silicic acid is controlled by the solubility

8 equilibrium of amorphous silica, shown in equation 3:

$$
\mathrm{SiO}_{2}(\mathrm{am})+2 \mathrm{H}_{2} \mathrm{O}(\mathrm{l}) \Leftrightarrow \mathrm{Si}(\mathrm{OH})_{4}(\mathrm{aq})
$$

9 Precipitation of amorphous silica instead of more stable quartz can be

10 considered as a manifestation of Ostwald's rule of stages. The equilibrium

11 constant of reaction 3 and solubility of amorphous silica are related through

12 equation

$$
K=\frac{a_{\mathrm{Si}(\mathrm{OH})_{4}}}{a_{\mathrm{H}_{2} \mathrm{O}}{ }^{2}}
$$

14 where $a_{\mathrm{Si}(\mathrm{OH}) 4}$ is the equilibrium activity of silicic acid and $a_{\mathrm{H} 2 \mathrm{O}}$ is the

15 equilibrium activity of water. At infinite dilution, the equilibrium constant 
1 approaches the solubility of silica. At room temperature $K$ is on the order of

$210^{-3} \mathrm{M}$, but the solubility is heavily affected by temperature [12] and

3 presence of electrolytes in the solution [13]. Increase in temperature

4 increases the solubility, whereas increase in ionic strength decreases it. This

5 due to increased hydration energy of silica as the activity of water

6 decreases [14].

7 Precipitation of silica proceeds via polymerization of monomeric silicic

8 acid units. Initially short linear structures are formed, which then condense

9 to small ring-like polymers. Internal condensation of the cyclic silicic acid

10 molecules leads to formation of small spherical nanoparticles that also act

11 as nuclei for the precipitation. In acidic solutions, $\mathrm{pH}<2$, polymerization

12 proceeds mainly by addition of monomeric silicic acid to larger polymers

13 [15]. It is known that particles suspended in a solution can grow by

14 Ostwald ripening, ie. dissolution of smaller, more soluble particles and the

15 following deposition on larger particles [16]. Rate of the ripening process is

16 controlled by the solubility of the bulk matter [17]. As is shown in this

17 work, however, high ionic strength of the solution decreases the already

18 low solubility of silica, and in the short time-scale of the precipitation,

19 Ostwald ripening is likely to be negligible. 
1 Precipitation process continues with aggregation of polymerized silica

2 particles. It was shown by Cooper [11] that initial silicic acid concentration

3 and supersaturation state control the precipitation product, both in batch

4 and continuous precipitation. At low supersaturation, solid well filterable

5 aggregates form. Increasing the initial silicic acid concentration leads to

6 formation micro-gel, gelatinous particles that also hinder the filterability.

7 Even higher supersaturation leads to formation of silicic acid gel.

8 Kinetics of the polymerization and precipitation process have been

9 considered by multiple authors, but there are large discrepancies between

10 reported kinetic regimes. Reaction rates varying in order from 1 to 5 with

11 respect to dissolved silicic acid have been reported, on some occasions with

12 a change in order as a function of $\mathrm{pH}$ [18-29]. Although some studies have

13 been made at low to extremely low $\mathrm{pH}$ values, based on our literature

14 survey, no studies have considered the high ionic strengths typically met in

15 hydrometallurgical processes. Most of the studies on silica precipitation

16 kinetics have focused on simple systems of geochemical interest.

\section{Results and Discussion}

18 The thermodynamic calculation software ChemSheet was used in this work

19 to model the solubility of silica in concentrated metal sulfate solutions [30].

20 ChemSheet provides a flexible spreadsheet interface powered by a 
1 ChemApp-based Gibbs energy minimization routine. The excess Gibbs

2 energies of the solute species were modelled with the Pitzer model using

3 temperature-dependent parameters. The neutral-ion interaction parameters

4 between aqueous silica and solute ions, $\lambda_{\mathrm{SiO} 2-j}$, were approximated from the

5 effective electrostatic radii of the ions using equations presented by

6 Azaroual et al [31] and Accornero \& Marini [32], who showed that for

7 many metal cations there exists a clear relationship between $\lambda_{\text {SiO2-j }}$ and the

8 cations effective electrostatic radii. The electrostatic radii were calculated

9 from the equations presented by Shock et al [33]. Exceptions were $\lambda_{\text {SiO2-SO4 }}$

10 and $\lambda_{\mathrm{SiO} 2-\mathrm{H}}$, for which the data was taken directly from Azaroual et al [31].

11 Fig. 1 shows solubility of silica in pure water as predicted by ChemSheet as

12 a function of temperature. Values collected from literature are shown for

13 comparison [12,34-36]. As can be seen, agreement between the model and

14 the reported values is good. Solubility predicted by the regression equation

15 of Gunnarsson \& Arnórsson is also shown [12]. The two curves agree

16 within the uncertainty of presented measurements. Fig. 2 shows the

17 correlation between calculated and measured solubilities both in pure water

18 and electrolyte solutions. Data shown is from this work and from literature

$19[12,37,38]$. Results from this work were also included. Again, the 
1 correlation is good in general, even though concentrated electrolyte

2 solutions were included.

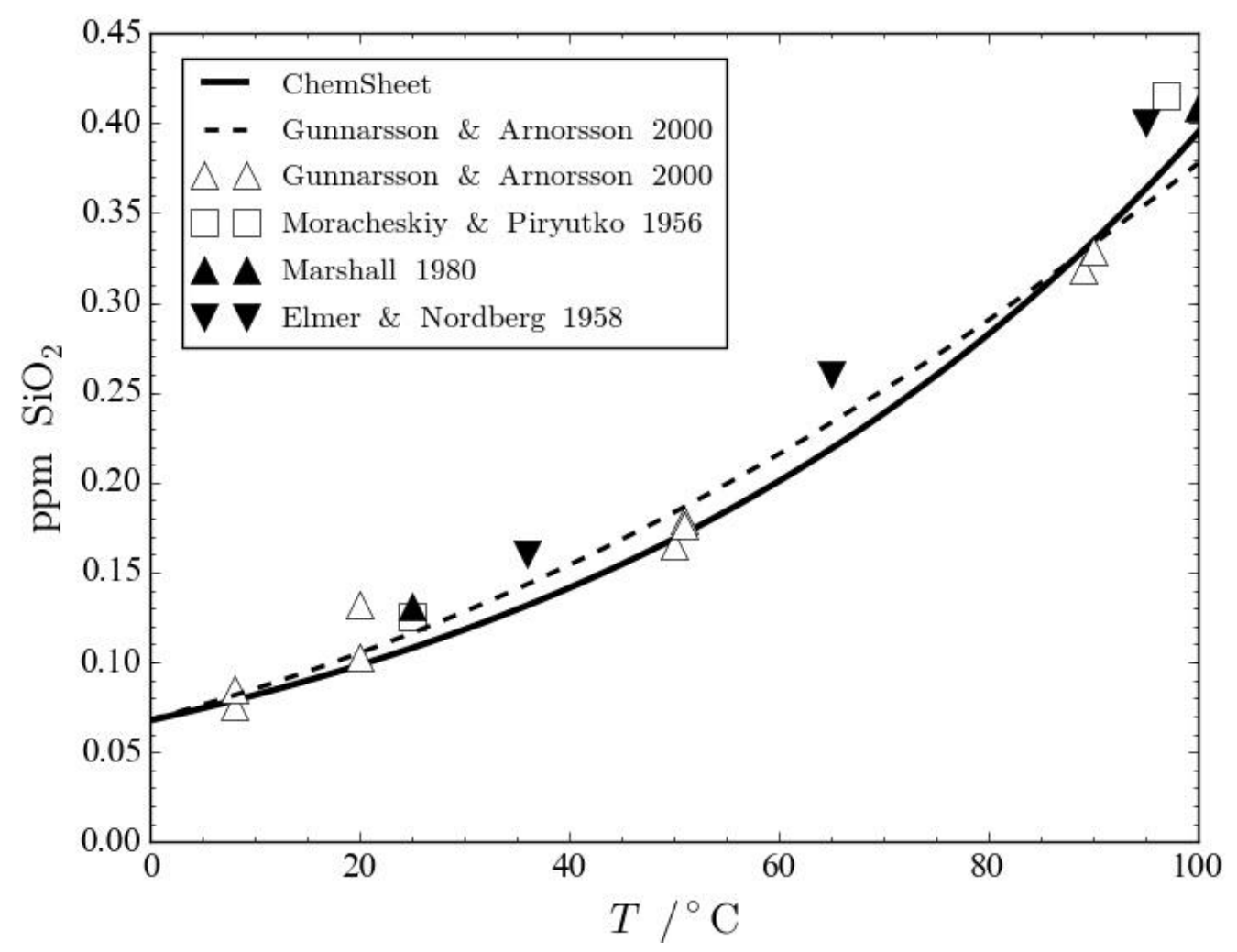

4 Fig. 1 Solubility of silica as a function of temperature. Values calculated

5 with ChemSheet compared to values collected from literature [12,34-36]. 


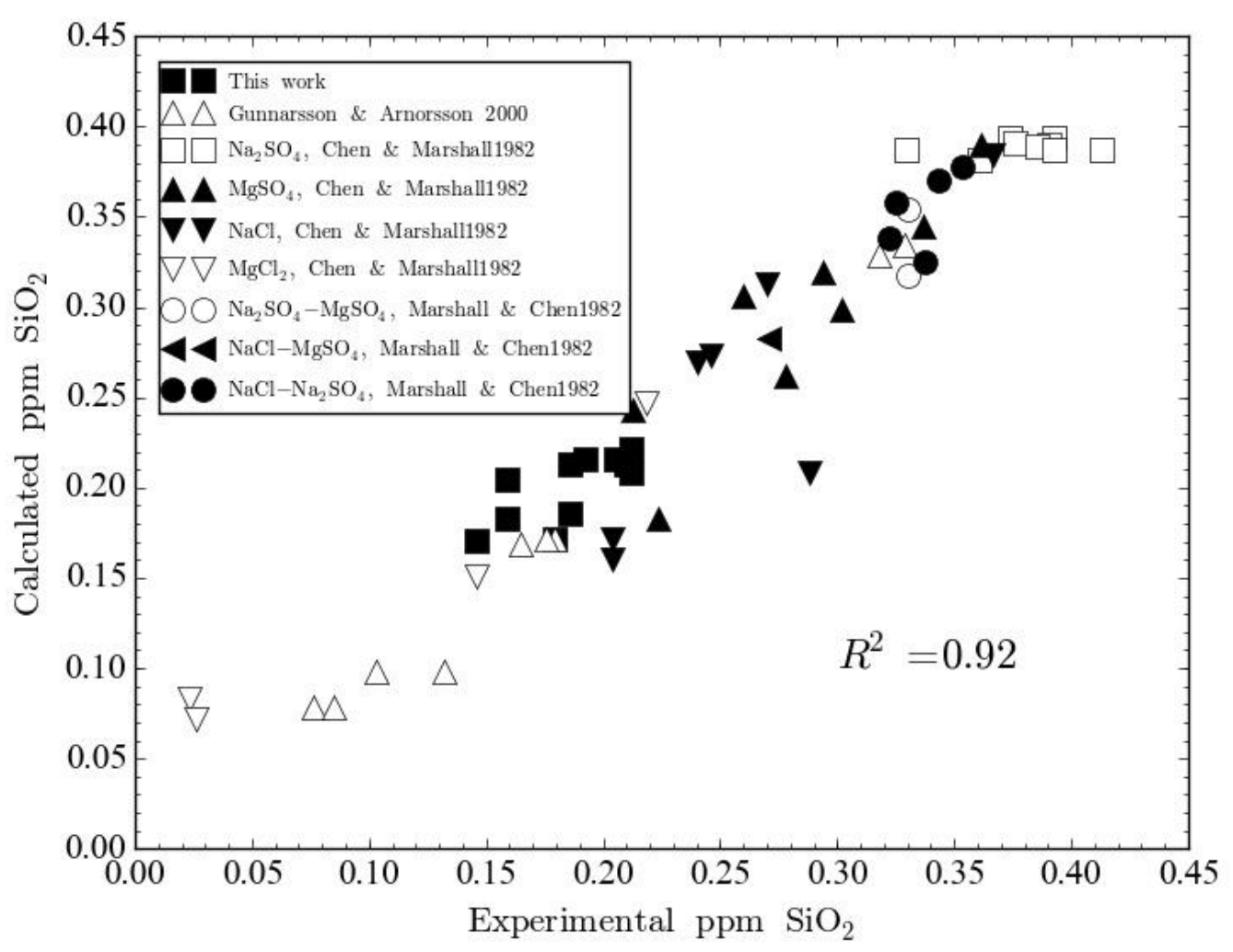

2 Fig. 2 Correlation between measured and calculated solubilities. Data from

3 this work and literature $[12,37,38]$.

4 Based on our measurements, at the operating conditions of the hot acid

5 leach, solubility of silica is lowered to approximately one half of that in

6 pure water, ie. approximately $200 \mathrm{ppm}$. This due to the high electrolyte

7 content of the solution. Presence of electrolytes decreases the activity of

8 water and interferes with the hydration of silica, effectively lowering its

9 solubility. A rather clear relationship can be observed between the ionic

10 strength of the solution, calculated from the measured concentrations, and

11 the solubility of silica. Fig. 3 shows solubility of silica in metal sulfate 
1 solutions as a function of ionic strength. Figure includes results from this

2 work and from Chen \& Marshall [37], Gunnarsson \& Arnórsson [12] and

3 Cooper [11]. Salting-out of silica is apparent. The solid curve was

4 calculated with ChemSheet using different levels of dilution for the average

5 composition of solutions used in this work. The model results moderately

6 agree with the experimental results. The solubility is to some degree

7 independent of the specific composition of the solution. This is most likely

8 because the ionic strength is mostly defined by zinc and sulfate ions, the

9 two most abundant components. It should also be noted that the neutral-ion

10 interaction coefficients were of similar magnitude for all considered metals.

11 This implies that ionic strength of the metal sulfate containing process

12 solutions can be used as an indicator for the solubility of silica. 


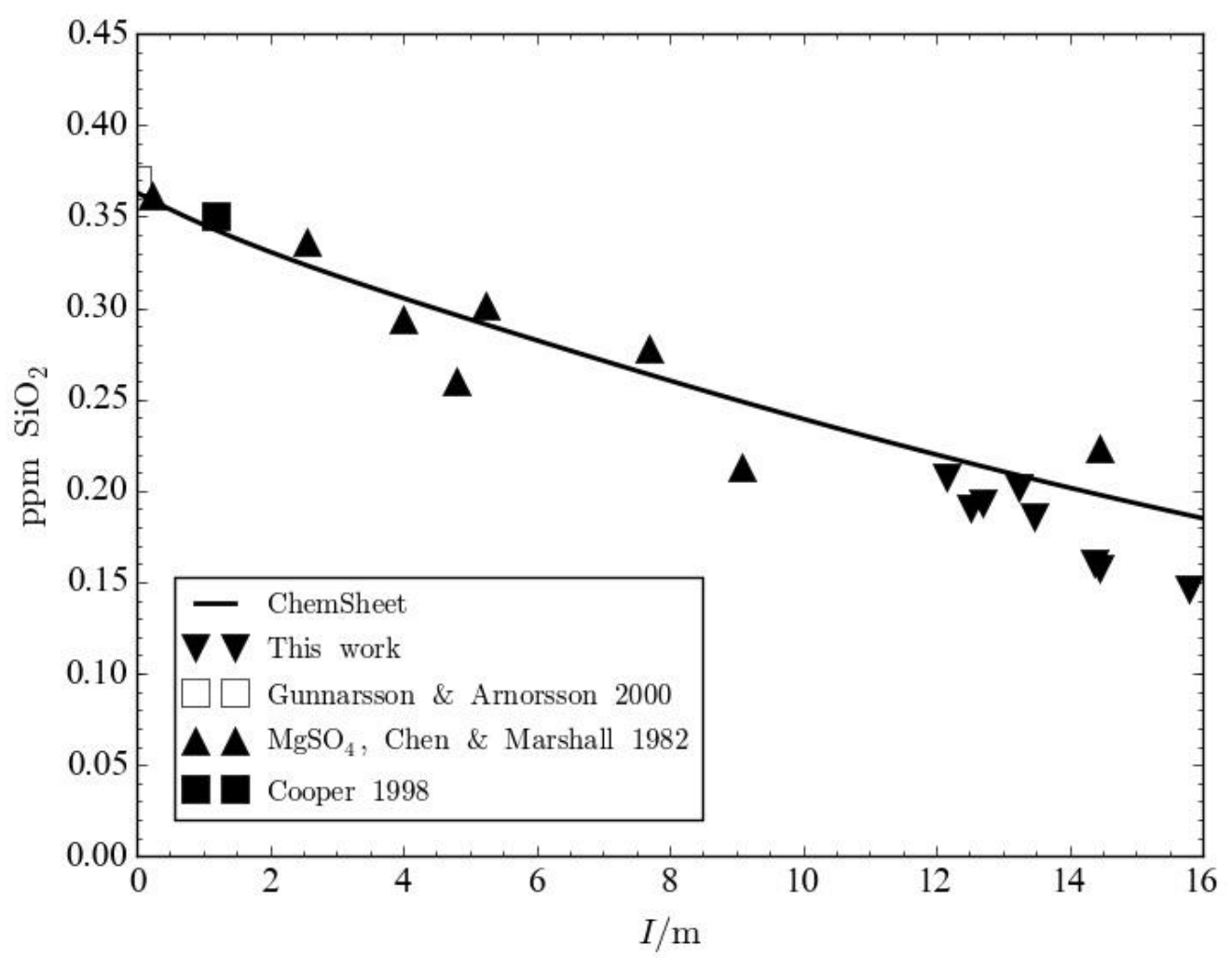

1

$I / \mathrm{m}$

2 Fig. 3 Solubility of silica in metal sulfate solutions as function of ionic

3 strength. Results from Chen \& Marshall [37] at $100{ }^{\circ} \mathrm{C}$, others at $95^{\circ} \mathrm{C}$

4 [11]. $\square$ was calculated from the equation presented by Gunnarsson \&

5 Arnórsson [12].

6 Concentration of soluble silica was followed on regular intervals during all

7 the precipitation experiments. Fig. 4 shows the typical precipitation curve

8 for model solutions. An induction period, during which the concentration of

9 soluble silica decreases rather slowly, is observed for the first $20 \mathrm{~h}$. This is

10 followed by a more rapid precipitation phase, and in 5-6 $\mathrm{h}$ silica

11 concentration reaches equilibrium level. The shape and timescale of these

12 precipitation curves agree well with results of Cooper [12]. However, the 
1 solubility level is much lower than the $350 \mathrm{ppm} \mathrm{SiO}_{2}$ reported, most likely

2 due to the higher ionic strength as the calculations above showed.

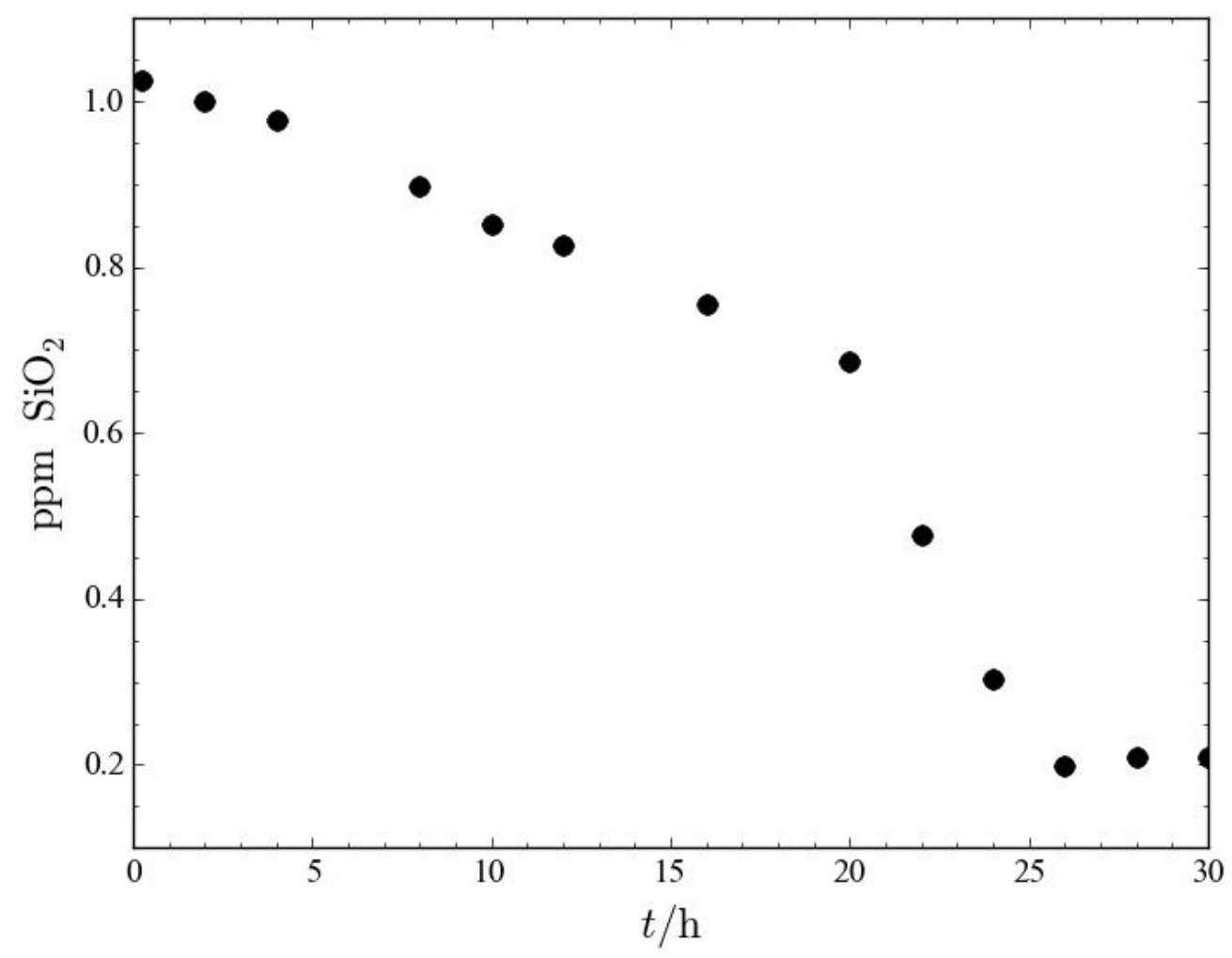

3 Fig. 4 Precipitation curve of silica for a synthetic solution. Note the almost

4 linear decrease in soluble silica concentration during the induction period.

5 For the authentic solutions, no induction period was observed. This could

6 be caused by the pre-existing silica nuclei and suspended solids in the

7 solution. Thus the nucleation phase is circumvented by direct deposition of

8 soluble silica on the existing active surfaces. This leads to only an

9 exponential decay of silicic acid concentration towards equilibrium

10 concentration being observed. The exponential decay implies a kinetic 
1 regime first order with respect to soluble silica. This is in agreement with

2 the fact that growth of colloidal silica particles is of the first order with

3 respect to monomeric silicic acid [39]. Weres et. al observed that increase

4 in ionic strength increases the rate of particle growth and precipitation, and

5 concluded it was due to change in degree of surface protonation [29]. From

6 our results, however, no clear relationship between precipitation rate and

7 ionic strength could be established.

8 Equation 5 shows the rate-law used to model the kinetics of silica

9 precipitation.

$$
\frac{d c_{\mathrm{Si}(\mathrm{OH})_{4}}}{d t}=k\left(c_{\mathrm{Si}(\mathrm{OH})_{4}}^{*}-c_{\mathrm{Si}(\mathrm{OH})_{4}}\right)
$$

11 Solution of differential equation 5 is given by equation 6 .

$$
c_{\mathrm{Si}(\mathrm{OH})_{4}}(t)=\left(c_{0}-c_{\mathrm{Si}(\mathrm{OH})_{4}}^{*}\right) e^{-k t}+c_{\mathrm{Si}(\mathrm{OH})_{4}}^{*}
$$

13 Equation 6 was fitted to the experimental data using a non-linear fitting

14 algorithm. Goodness of fit and the applicability of the model was judged by

15 analysis of residuals and calculated $R^{2}$ values. Reaction rate constant $k$, 
1 initial silicic acid concentration $c_{0}$ and equilibrium concentration $c^{*}$ were

2 taken as the fitting parameters. In general, the obtained fit was excellent.

\section{Effect of silicic acid concentration}

4 Effect of initial silicic acid concentration was investigated by adding

5 synthetic willemite and a stoichiometric amount of sulfuric acid to

6 authentic process solutions at the start of experiment. The initial

7 concentrations were $0.524,0.736$ and $2.328 \mathrm{~g} \mathrm{SiO}_{2} \mathrm{dm}^{-3}$. It was observed

8 that at low concentrations, the precipitation reaction follows the proposed

9 rate law. At higher concentration, however, the precipitation somewhat

10 deviates from this behavior, and possibly a short induction phase is

11 observed. The latter part of the precipitation curve provided an acceptable

12 fit to the proposed rate law. However, the fit resulted to considerably larger

13 reaction rate constant $\left(0.285 \mathrm{~s}^{-1}\right)$ than for the lower initial concentrations

14 (on average $0.085 \mathrm{~s}^{-1}$ ). Precipitation curves for different initial silica

15 concentrations are shown in Fig. 5.

16 The induction phase was observed likely due to the large amount of added

17 willemite. High concentration of silicic acid is liberated, leading to similar

18 set-up as in the experiments with model solutions. The decrease in silicic

19 acid concentration during the induction phase, however, was much more

20 rapid than in the model solutions. This is could be due to pre-existing silica 
1 nuclei and other suspended solids, that allow for heterogenous nucleation

2 to take place. It is also interesting to note that regardless of the measured

3 initial silicic acid concentration, solubility level was achieved in

4 approximately $6 \mathrm{~h}$.

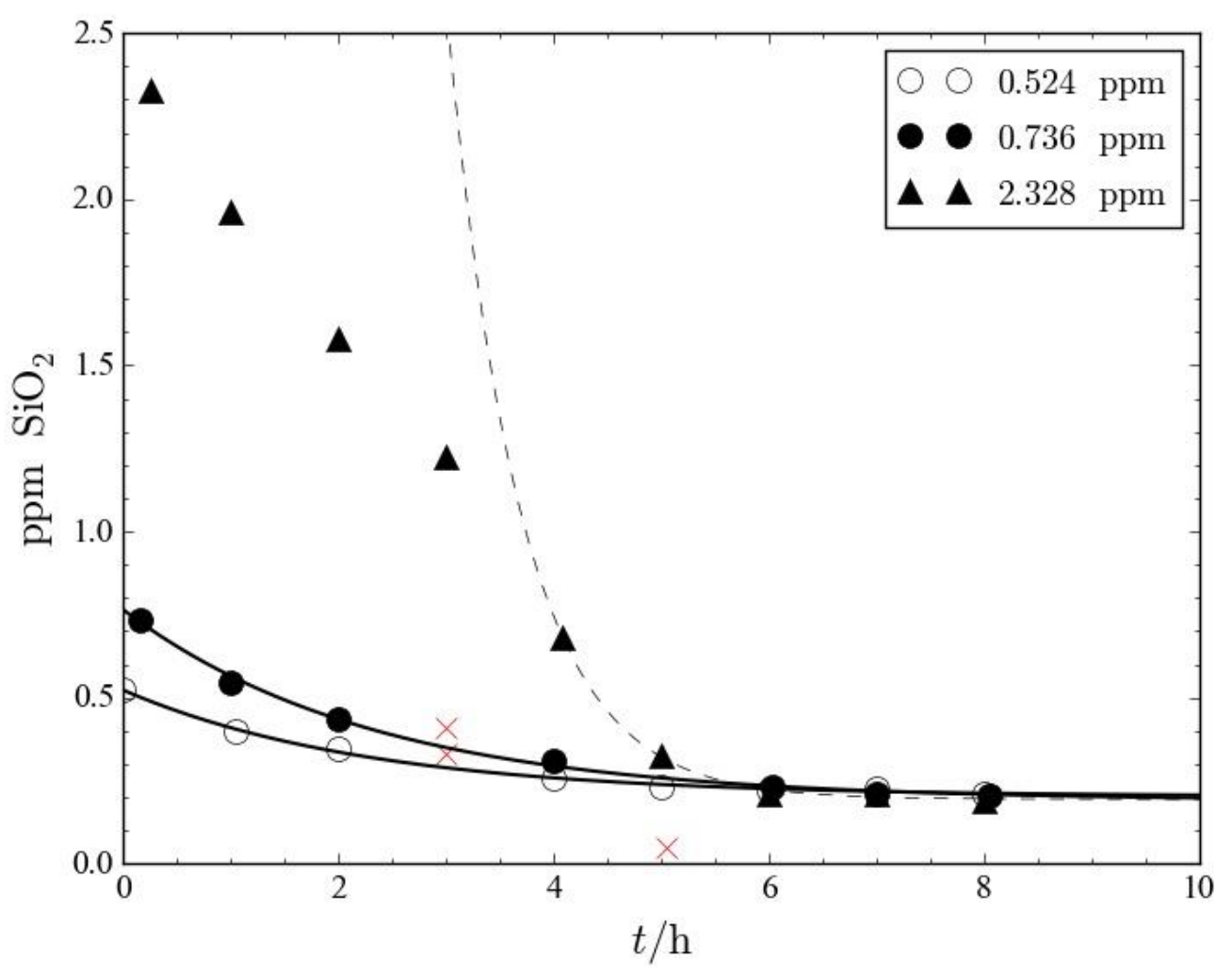

6 Fig. 5 Precipitation curves with varying initial concentration of soluble

7 silica. -- is the fit to the latter part of precipitation curve with initial silica

8 concentration of $2.328 \mathrm{ppm}$. 
1 A set of experiments was performed to study the effect of sulfuric acid

2 concentration on the rate of precipitation. Experiments were carried out

3 with 75 and $100 \mathrm{~g} \mathrm{H}_{2} \mathrm{SO}_{4} \mathrm{dm}^{-3}$. Fig. 6 shows comparison between the

4 measured precipitation curves.

5 It is known that at low $\mathrm{pH}$, protons catalyze the polymerization reaction of

6 silicic acid and precipitation of silica, and increase in acid concentration

7 increases the rate of precipitation and gelling at low $\mathrm{pH}[11,40,41]$. A linear

8 relationship was observed between sulfuric acid concentration and reaction

9 rate constant $k$, on the investigated concentration range. The results are

10 presented graphically in Fig. 7. Our result is in stark contrast with

11 literature, since Gorrepati et al reported an exponential relationship

12 between hydrochloric acid concentration and reaction rate [41]. Hurd \&

13 Barclay reported an exponential relationship between sulfuric acid

14 concentration and reaction rate constant [40]. This can be partly due to

15 different kinetic models used; Hurd \& Barclay calculated reaction rate

16 constant as the inverse of precipitation time, and Gorrepati et al used a

17 model based on a fast second order polymerization followed by a

18 aggregation step modelled with Smoluchowksi equation. 


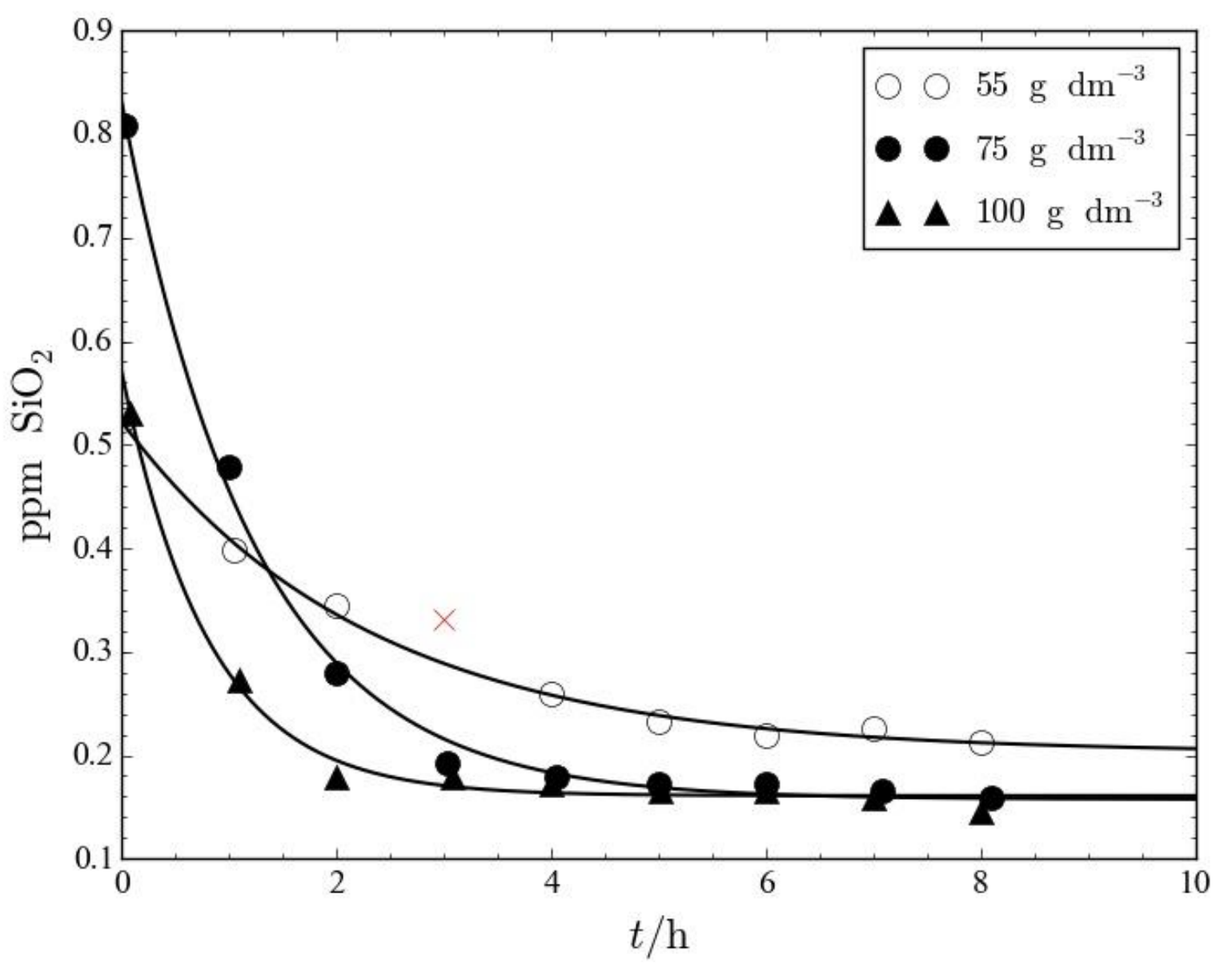

Fig. 6 Precipitation curves with varying sulfuric acid concentrations. 


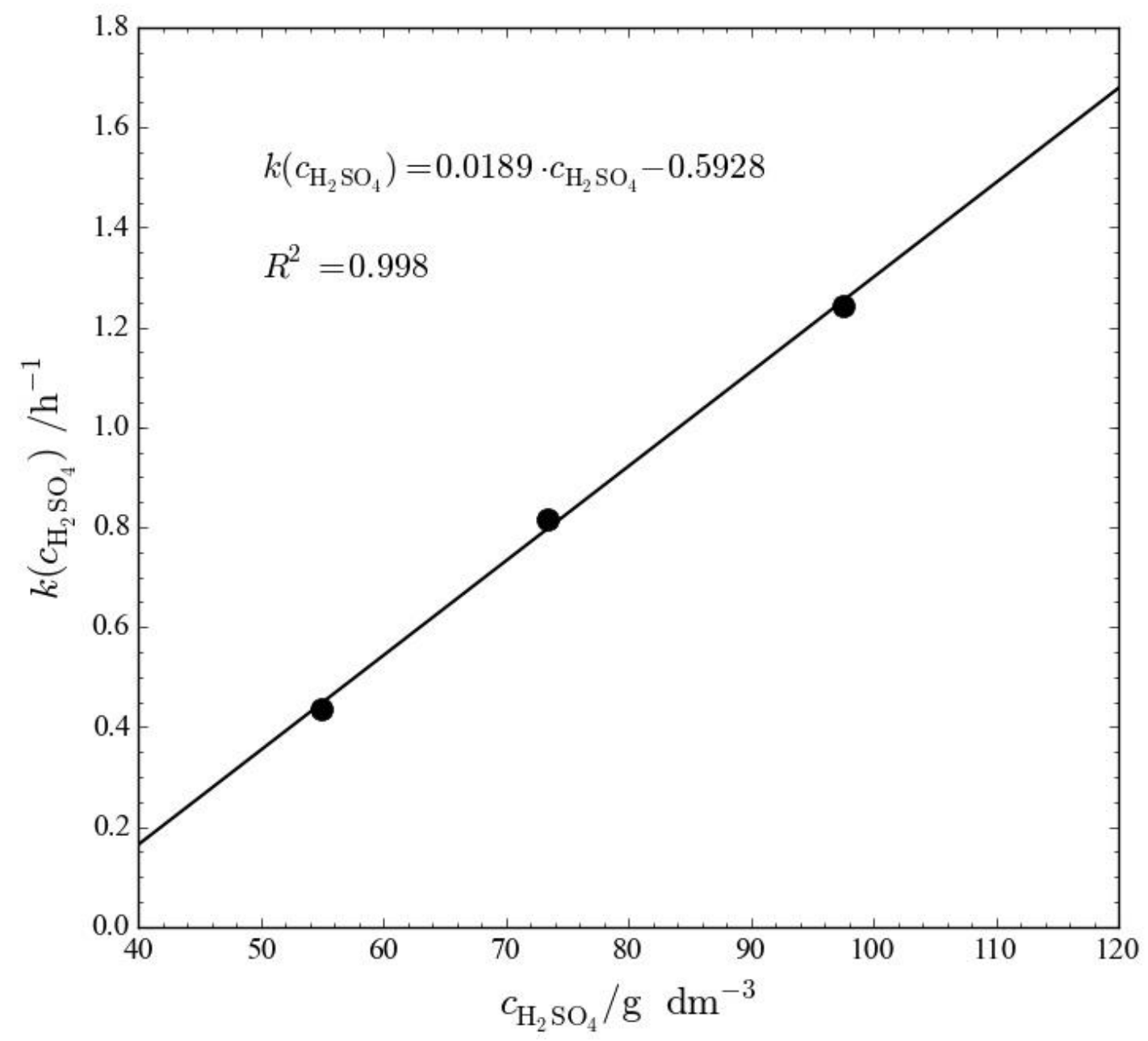

Fig. 7 A linear relationship was observed between the reaction rate constant $k$ and sulfuric acid concentration.

\section{Activation energy of precipitation}

3 Precipitation experiments were performed at temperatures 80, 85, 90, 95

4 and $100{ }^{\circ} \mathrm{C}$. Precipitation curves at 90,95 and $100{ }^{\circ} \mathrm{C}$ are shown in Fig 8 .

5 At $80{ }^{\circ} \mathrm{C}$, an induction phase was observed, and the experiment was 
1 terminated before rapid precipitation had occurred. High initial silicic acid

2 concentration, $2.0 \mathrm{~g} \mathrm{dm}^{-3}$, was also measured. The high silicic acid

3 concentration, as explained above, together with the lowered temperature

4 most likely lead to slow nucleation and an observable induction phase. It is

5 left for further studies to find the relative importance of these two factors.

6 Irregularities were observed, when drawing the Arrhenius plot. Reaction

7 rate constant was higher at $85^{\circ} \mathrm{C}$ than at 90 or $95^{\circ} \mathrm{C}$. It was excluded from

8 the data set, but this lead to abnormally high apparent activation energy of

$9196 \mathrm{~kJ} \mathrm{~mol}^{-1}$. The fit for the data at $100{ }^{\circ} \mathrm{C}$ was also not satisfactory. After

10 excluding the rate constant at $100{ }^{\circ} \mathrm{C}$, a value of $61.7 \mathrm{~kJ} \mathrm{~mol}^{-1}$ was

11 obtained. The value is a crude estimate since it was calculated essentially

12 based on just two temperatures. It, however, points towards a reaction-

13 controlled mechanism for the precipitation reaction. This agrees with the

14 fact that silica solutions are kinetically stable at low $\mathrm{pH}$, a diffusion-

15 controlled mechanism is thus unlikely. It is also comparable to values

16 previously reported in the literature; $61 \mathrm{~kJ} \mathrm{~mol}^{-1}$ by Carrol et. al [42], 54.8

$17 \mathrm{~kJ} \mathrm{~mol}^{-1}$ by Fleming [43] and $49.8 \mathrm{~kJ} \mathrm{~mol}^{-1}$ by Rimstidt and Barnes [44],

18 but it should be mentioned that these observation were made for entirely

19 different solution media. Fig. 9 shows the Arrhenius plot. 


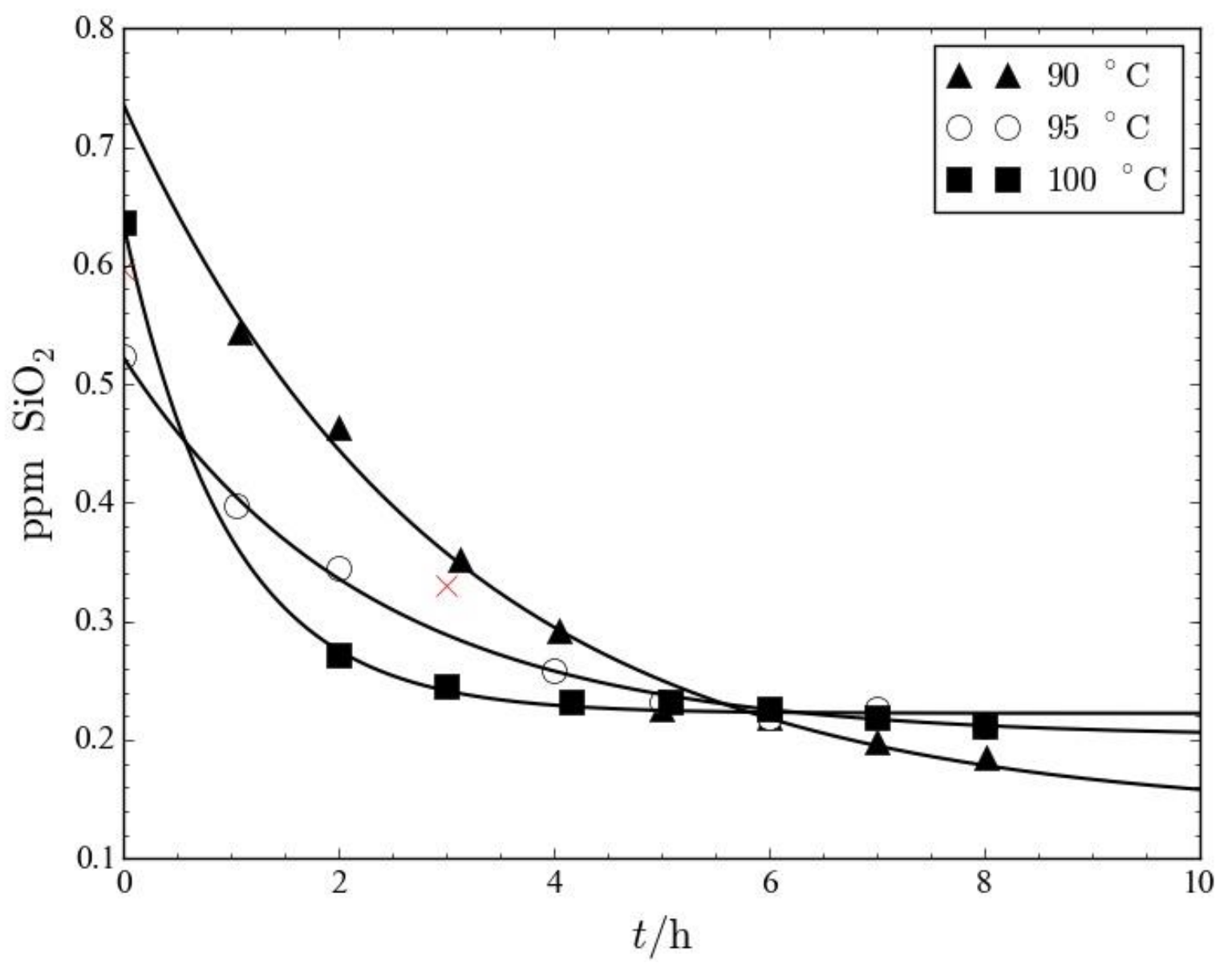

Fig. 8 Precipitation curves measured at 90, 95 and $100{ }^{\circ} \mathrm{C}$. 


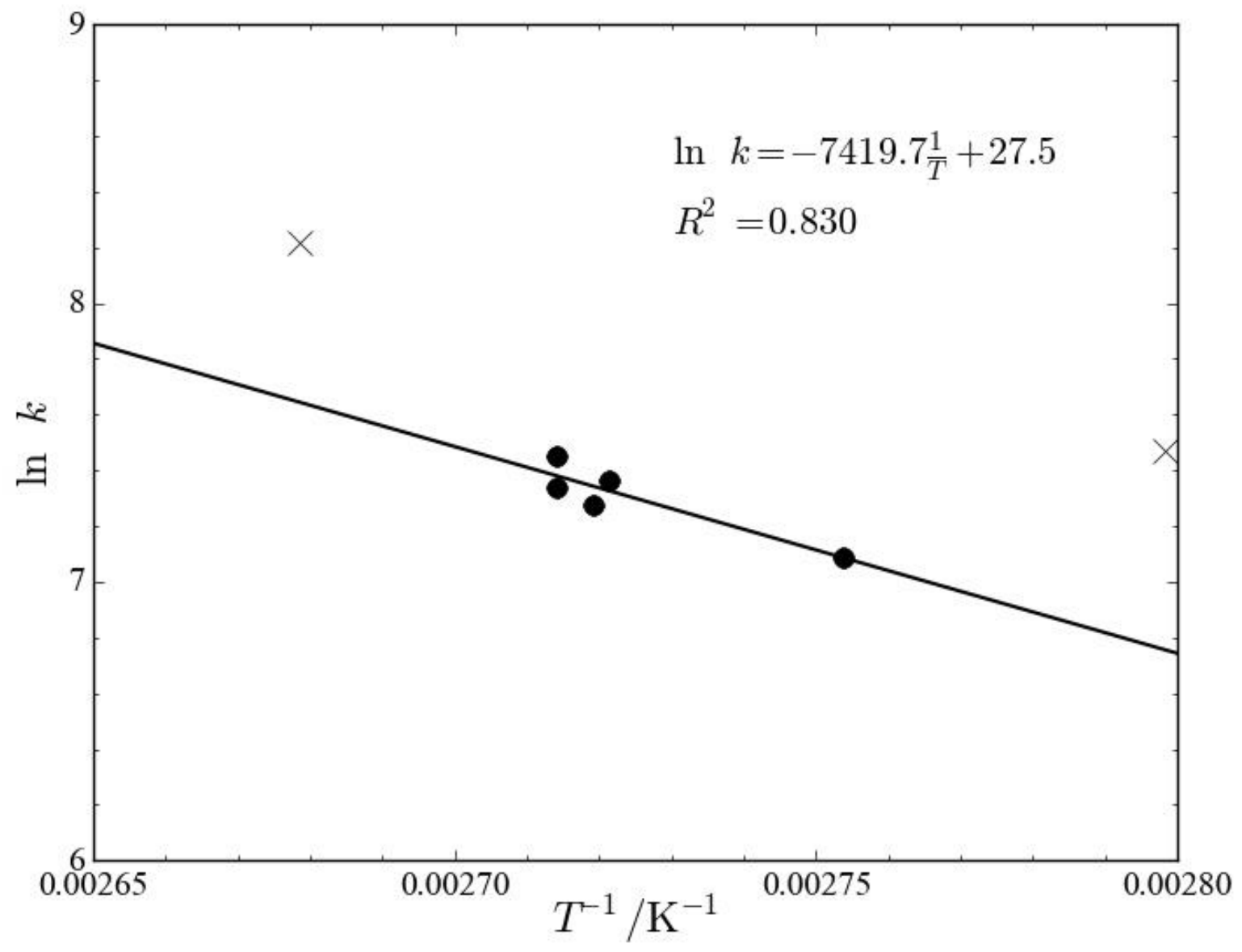

Fig. 9 Arrhenius plot for the precipitation of silica. ${ }^{\times}$are the rejected data points (see for text).

\section{Conclusions}

2 This work has several implications for hydrometallurgic industry. Behaviour

3 of aqueous silica is greatly altered by high concentrations of soluble metals.

4 During hot acid leach of zinc minerals, solubility of silica is approximately

5 half of that in pure water. This leads easily to high supersaturation and

6 gelling. Under normal operating conditions, precipitation is complete in 
1 approximately 5-6 hours. By increasing the acid concentration or solution

2 temperature, it possible to complete the precipitation in only 1-2 hours. Good

3 agreement was achieved between experimental data and the thermodynamic

4 and kinetic models. It appears that ionic strength calculated from the solution

5 composition can be used to predict silica solubility. Based on pseudo-first

6 order rate law, apparent activation energy of precipitation was estimated to

7 be $61.7 \mathrm{~kJ} \mathrm{~mol}^{-1}$, which is in moderate agreement with the literature and 8 suggests a reaction-controlled mechanism for precipitation of silica.

\section{Experimental}

\section{Materials}

12 Willemite used in this work was synthesised from $\mathrm{ZnO}(\geq 99.0 \%$, Sigma-

13 Aldrich), $\mathrm{SiO}_{2}$ (purum p.a., Sigma-Aldrich) and $\mathrm{NaOH}(\geq 99.0 \%$, Merck).

14 Model solutions were made by dissolving reagent grade metal sulfates into 15 a sulfuric acid solution that was then diluted to volume of $0.9 \mathrm{dm}^{3}$. Reagents 16 used in this work were $\mathrm{Al}_{2}\left(\mathrm{SO}_{4}\right)_{3} \cdot 16 \mathrm{H}_{2} 0$ ( $\geq 95.0 \%$, Fluka Analytical), $17 \mathrm{Fe}_{2}\left(\mathrm{SO}_{4}\right)_{3} \cdot \mathrm{xH}_{2} \mathrm{O}\left(21-23 \% \mathrm{Fe}\right.$, Sigma-Aldrich), $\mathrm{MgSO}_{4} \cdot 7 \mathrm{H}_{2} \mathrm{O}(\geq 99.5 \%$, Oy 18 FF-Chemicals $\mathrm{Ab}$ ), $\mathrm{MnSO}_{4} \cdot \mathrm{H}_{2} \mathrm{O}\left(\geq 99.0 \%\right.$, Sigma-Aldrich), $\mathrm{ZnSO}_{4} \cdot 7 \mathrm{H}_{2} \mathrm{O}$ 19 ( $\geq 99.0 \%$, Sigma-Aldrich), $\mathrm{H}_{2} \mathrm{SO}_{4}$ (95.0\%, Merck). Authentic solutions 20 were obtained from a local zinc plant. 


\section{Apparatus}

2 A custom-made baffled stainless steel reactor was used as the reaction

3 vessel. Operating volume of the reactor was 11 . A pitched-blade impeller

4 with a ball-bearing was fitted through the reactor's lid along with a reflux

5 condenser, to prevent evaporation of the solution without build-up of

6 pressure. Air was bubbled through a vent at the bottom of the vessel to ensure

7 slightly oxidative environment. $\mathrm{pH}$ and RedOx-meter were used to monitor

8 the $\mathrm{pH}$ and reduction potential during precipitation. Temperature was

9 measured with a standard digital thermometer. The range of experimental

10 conditions covered in this work are presented in Table 1.

Table 1. Range of experimental conditions.

$\begin{array}{ll}\text { Temperature } & 80-100{ }^{\circ} \mathrm{C} \\ \text { Stirring speed } & 250 \mathrm{rpm} \\ \text { Air flow } & 0.5 \mathrm{dm}^{3} \mathrm{~min}^{-1} \\ \text { Sulfuric acid concentration } & 55-100 \mathrm{~g} \mathrm{H}_{2} \mathrm{SO}_{4} \mathrm{dm}^{-3}\end{array}$

13 Willemite synthesis

14 Willemite was synthesised by a sol-gel reaction followed by calcination. A 15 modified version of the method presented by Yatabe et al. was used [11, 45]. 
1 A solution of sodium silicate was slowly added to acidic solution of zinc

2 sulfate. A thick white precipitate formed, which was then left to settle for 24

3 h. It was then separated from the solution, washed twice and dried over night

4 at $105{ }^{\circ} \mathrm{C}$. Dried precipitate was calcined at $1100{ }^{\circ} \mathrm{C}$ for $12 \mathrm{~h}$ to transform

5 the amorphous zinc silicate to crystalline willemite.

6 Cooled product was washed twice with aqueous sodium hydroxide solution

7 to dissolve any excess silicon dioxide. After filtering and washing with

8 distilled water the product was dried at 105 for $24 \mathrm{~h}$. The final product was

9 characterised with XRPD. No major impurities were identified. The

10 synthesised willemite was ball-milled before use.

\section{Experiments with model solutions}

12 An acidic metal sulfate solution was prepared from the reagents. The

13 solution was heated in the reactor to the target temperature. Fine ground

14 willemite was added and timer started. Samples were taken regurarly and

15 filtrated through a $0.45 \mu \mathrm{m}$ syringe filter. Filtered samples were immediately

16 diluted with dilute sulfuric acid solution. Samples were analyzed later with

17 ICP-OES for $\mathrm{Si}, \mathrm{Zn}, \mathrm{Fe}, \mathrm{Al}, \mathrm{Mn}$ and $\mathrm{Mg} . \mathrm{pH}$, temperature and RedOx-

18 potential were measured regurarly. It is important to note that the measure

19 of soluble silica in this work was the total concentration that would pass the $20 \quad 0.45 \mu \mathrm{m}$ filter. 
1 Experiments with authentic solutions

2 The authentic solutions used were fresh from the process. The reaction vessel

3 was pre-heated to minimize the delay between taking the solution and

4 starting the experiment. After the solution inside the reactor reached target

5 temperature zone, timer was started. Possible additives, willemite or sulfuric

6 acid, were added at this point. Sampling was again done regularly, in the

7 same manner as described above. After terminating the experiment, the

8 processed solution was filtrated.

11 Acknowledgements

12

13 References

14 [1] Terry B (1983) Hydrometallurgy 10: 135

15 [2] Terry B (1983) Hydrometallurgy 10: 151

16 [3] Matthew IG, Elsner D (1977) Metall Trans B 8: 73

17 [4] Safari V, Arzpeyma G, Rashchi F, Mostoufi N (2009) Int J Miner

$18 \quad$ Process 93: 79

19 [5] Ikenobu S, Shimokawa K (1998) Method for processing zinc 
silicate-containg zinc crude material. European Patent 0851034 A1,

$2 \quad$ Jul 1, 1998

3 [6] Dufresne RE (1976) JOM 28: 8

4 [7] Radino HL (1957) Process of zinc extraction from ores comprising

5 soluble silicates by means of hydrometallurgy. Australian Patent $6 \quad 224,195$.

7 [8] Perry W (1966) Chem Eng 73: 182

8 [9] Queneau PB, Berthold CE (1986) Can Metall Q 25: 201

9 [10] Fugleberg SP, Poijärvi JTI (1979) Hydrometallurgical

10 treatment of soluble silicate-bearing zinc materials. US Patent

$114,148,862 \mathrm{~A}$.

12 [11] Cooper RMG (1998) Silica precipitation from electrolytic zinc

13 solutions. Ph.D. dissertation. Curtin University of Technology, $14 \quad$ Australia, 1998.

15 [12] Gunnarsson I, Arnórsson S (2000) Geochim Cosmochim Acta $16 \quad 64: 2295$

17 [13] Marshall WL, Chen CTA (1982) Geochim Cosmochim Acta 
46: 289

2

4

5

6

7

8

9

10

11

12

13

14

15

16

[14] Dove PM, Rimstidt JD (1994) In: Silica: Physical Behavior, Geochemistry and Material Applications. American Mineral Society.

[15] Shimada K, Tarutani T (1979) J Chromatogr 168: 4017

[16] Ostwald W. (1896) Lehrbuch der Allgemeinen Chemie. Leipzig, Germany.

[17] Wagner, C (1961) Z Elektrochem 35: 581

[18] Alexander GB (1954) J Am Chem Soc 76: 2094

[19] Baumann H (1959) Kolloid Z 162: 28

0 [20] Bishop AD, Bear JL (1972) Thermochim Acta 3: 399

1 [21] Conrad CF, Yasuhara H, Bandstra JZ, Icopini GA, Brantley

2 SL, Heaney PJ (2007) Geochim Cosmochim Acta 71: 531

3 [22] Crerar D, Axtmann EV, Axtmann RC (1981) Geochim

4 Cosmochim Acta 45: 1259

5 [23] Goto K (1956) J Phys Chem 60: 1007

6 [24] Icopini GA, Brantley SL, Heaney PJ (2005) Geochim 
$1 \quad$ Cosmochim Acta 69: 293

2 [25] Kitahara S (1960) Rev Phys Chem Jpn 30: 131

3 [26] Makrides AC, Turner M, Slaughter J (1980) J Colloid

$4 \quad$ Interface Sci 73: 345

5 [27] Okamoto G, Okura T, Goto K (1957) Geochim Cosmochim Acta 12: 123

7

[28] Rothbaum HP, Rhode AG (1979) J Colloid Interface Sci 71:

[29] Weres O, Yee A, Tsao L (1981) J Colloid Interface Sci 84: 379

[30] Koukkari P, Penttilä K, Hack K, Petersen S (2000) In:

11 Microstructures, Mechanical Properties and Processes Computer

12 Simulation and Modeling. Wiley-VHC, Weinheim.

13 [31] Azaroual M, Fouillac C, Matray JM (1997) Chem Geol 140:

$14 \quad 155$


[34] Morachevskiy YV, Piryutko MM (1956) Russ Chem Bull 5:

2 917

[35] Marshall W (1980) Geochim Cosmochim Acta 44: 907

[36] Elmer TH, Nordberg ME (1958) J Amer Ceram Soc 41: 517

[37] Chen CTA, Marshall W (1982) Geochim Cosmochim Acta 46:

6 279

7

[39] Tobler DJ, Shaw S, Liane GB (2009) Geochim Cosmochim

[40] Hurd CB, Barclay RW (1940) J Phys Chem 44: 847

[41] Gorrepati EA, Wongthahan P, Raha S, Fogler HS (2010)

Carroll S, Mroczek E, Alai M, Ebert M (1998) Geochim

Cosmochim Acta 62: 1379

16

[43]

Fleming BA (1986) J Colloid Interface Sci 110: 40

17

[44] Rimstidt JD, Barnes, HL (1980) Geochim Cosmochim Acta 
110: 40

6

7 Following the References section, Figure Captions (separated from the

8 actual figures), Tables, Schemes, and Figures should be collected to facilitate

9 the production process.

\section{Figure Captions}

12 Fig. 1 Solubility of silica as a function of temperature. Values calculated

13 with ChemSheet compared to values collected from literature [12,34-36].

14 Fig. 2 Correlation between measured and calculated solubilities.

15 Fig. 3 Solubility of silica in metal sulfate solutions as function of ionic 16 strength. Results from Chen \& Marshall [37] at $100{ }^{\circ} \mathrm{C}$, others at $95{ }^{\circ} \mathrm{C}$ [11].

17 Fig. 4 Precipitation curve of silica for a synthetic solution. Note the almost

18 linear decrease in soluble silica concentration during the induction period.

19 Fig. 5 Precipitation curves with varying initial concentration of soluble 20 silica.

21 Fig. 6 Precipitation curves with varying sulfuric acid concentrations. 
1 Fig. 7 A linear relationship was observed between the reaction rate constant

$2 \quad k$ and sulfuric acid concentration.

3 Fig. 8 Precipitation curves measured at 90,95 and $100{ }^{\circ} \mathrm{C}$.

4 Fig. 9 Arrhenius plot for the precipitation of silica. ${ }^{\times}$are the rejected data 5 points (see for text).

6

7

Table 1. Range of experimental conditions.

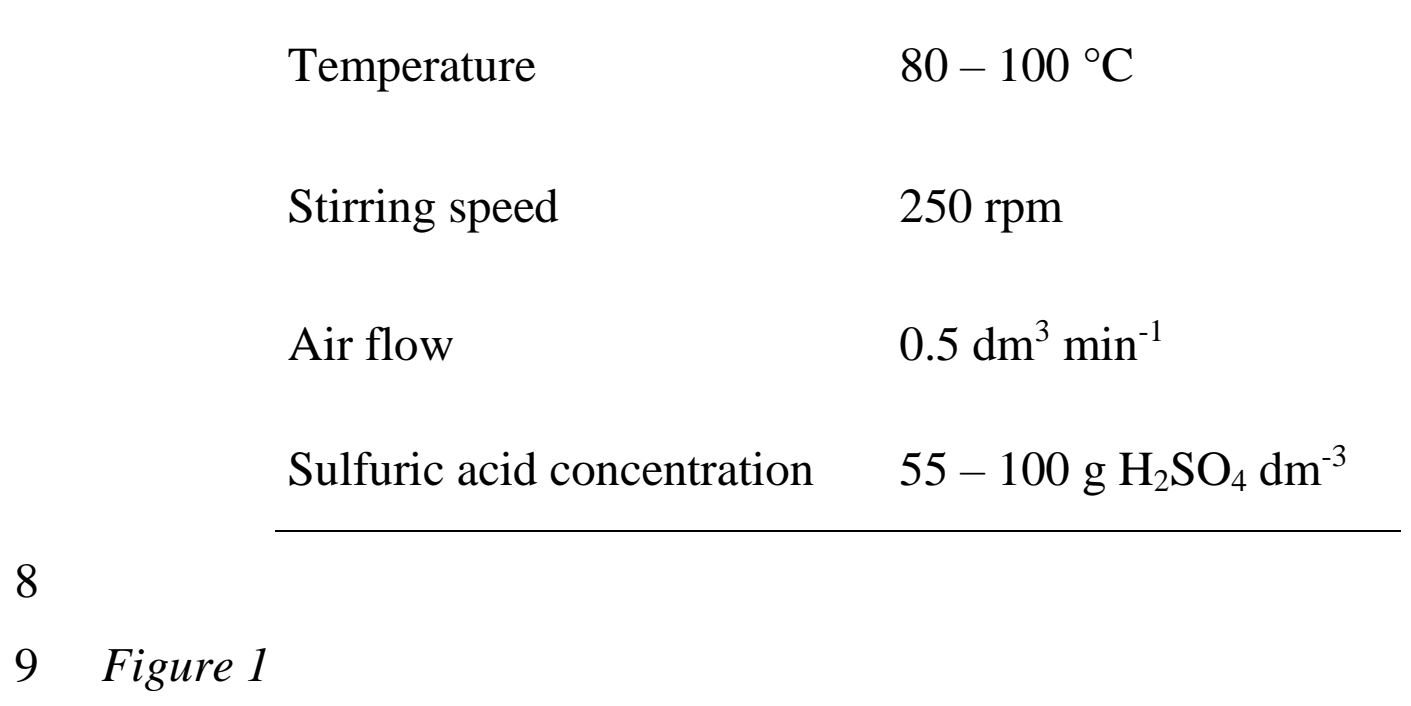




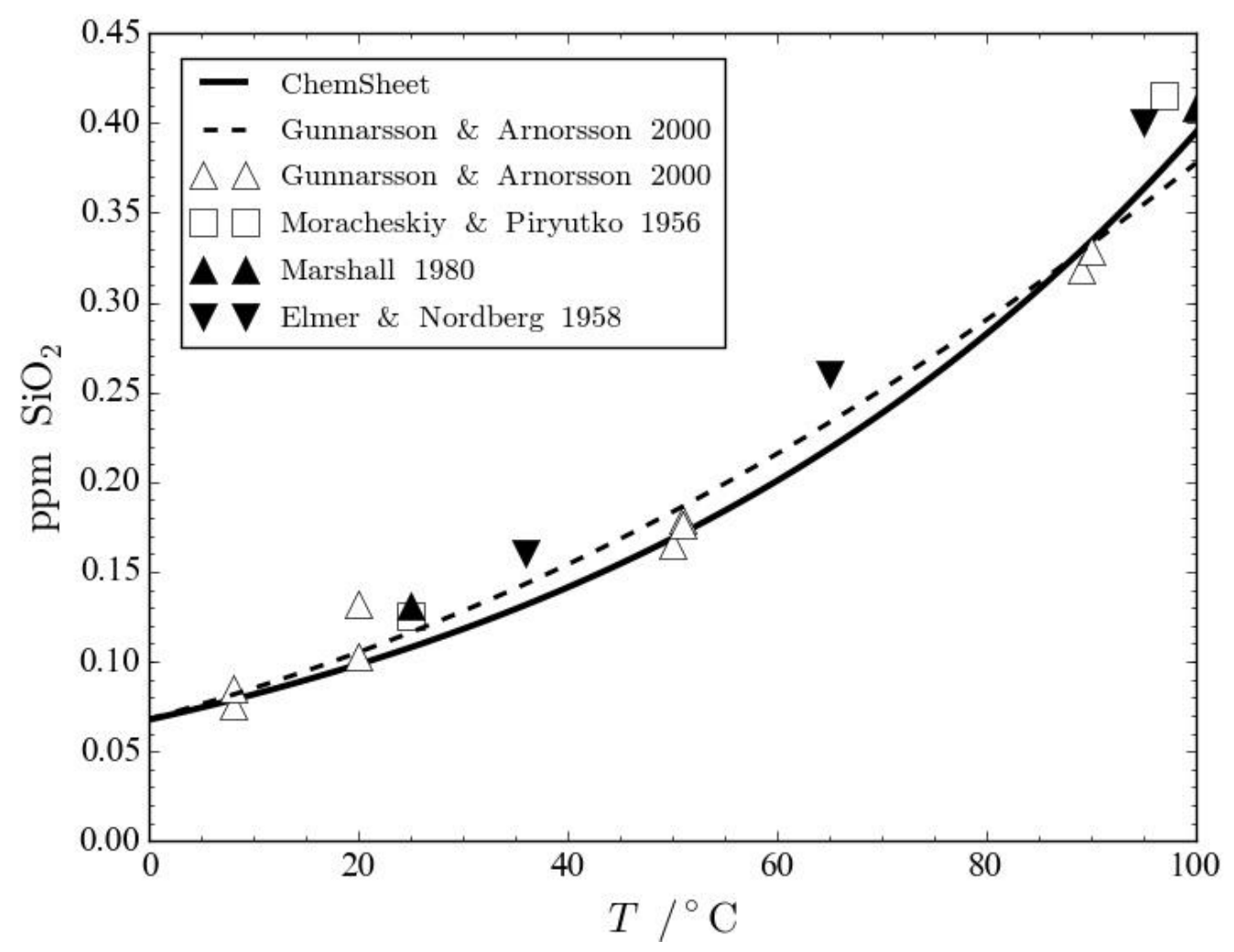

2

3

$4 \quad$ Figure 2 


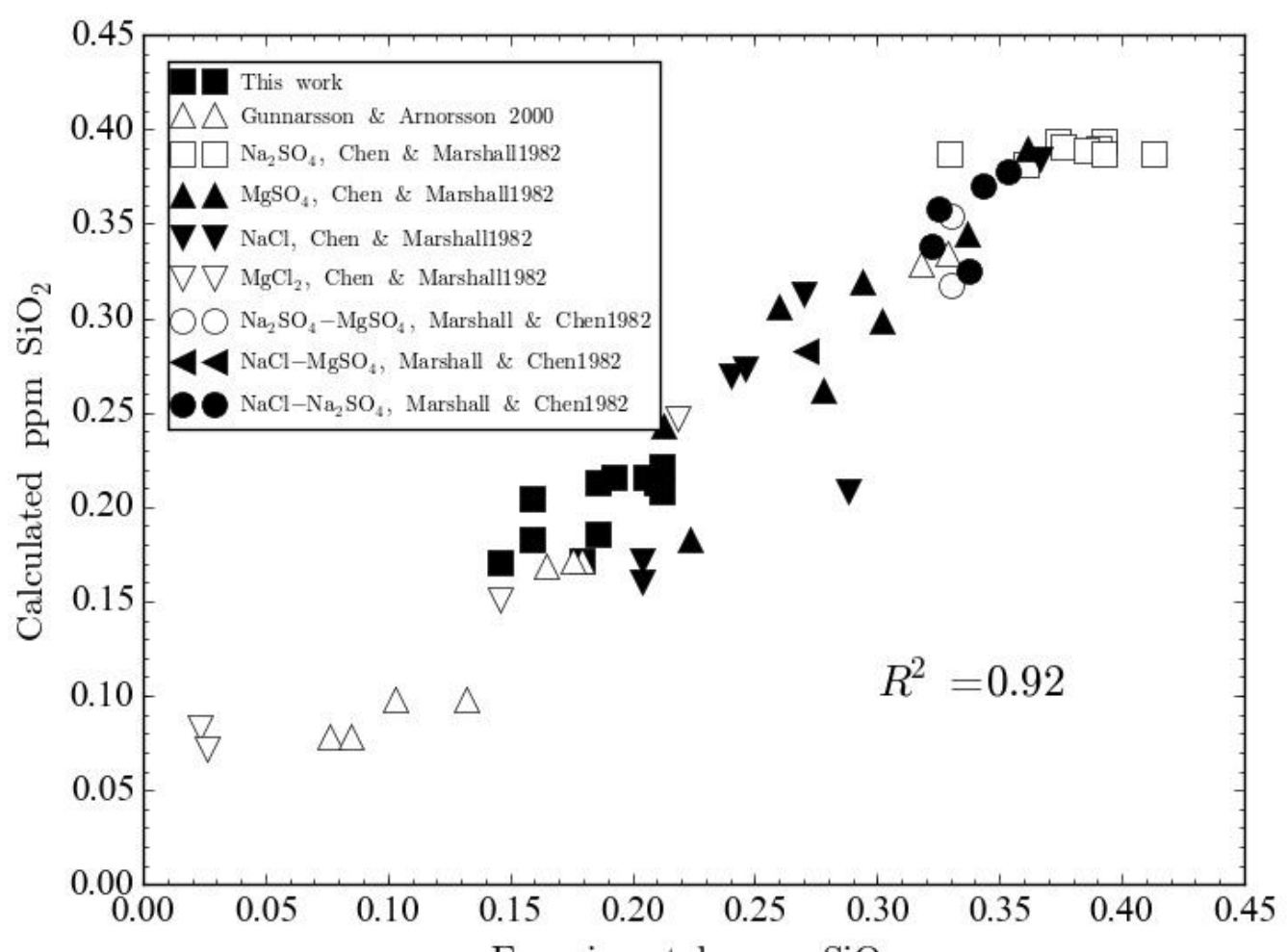




\section{$1 \quad$ Figure 3}

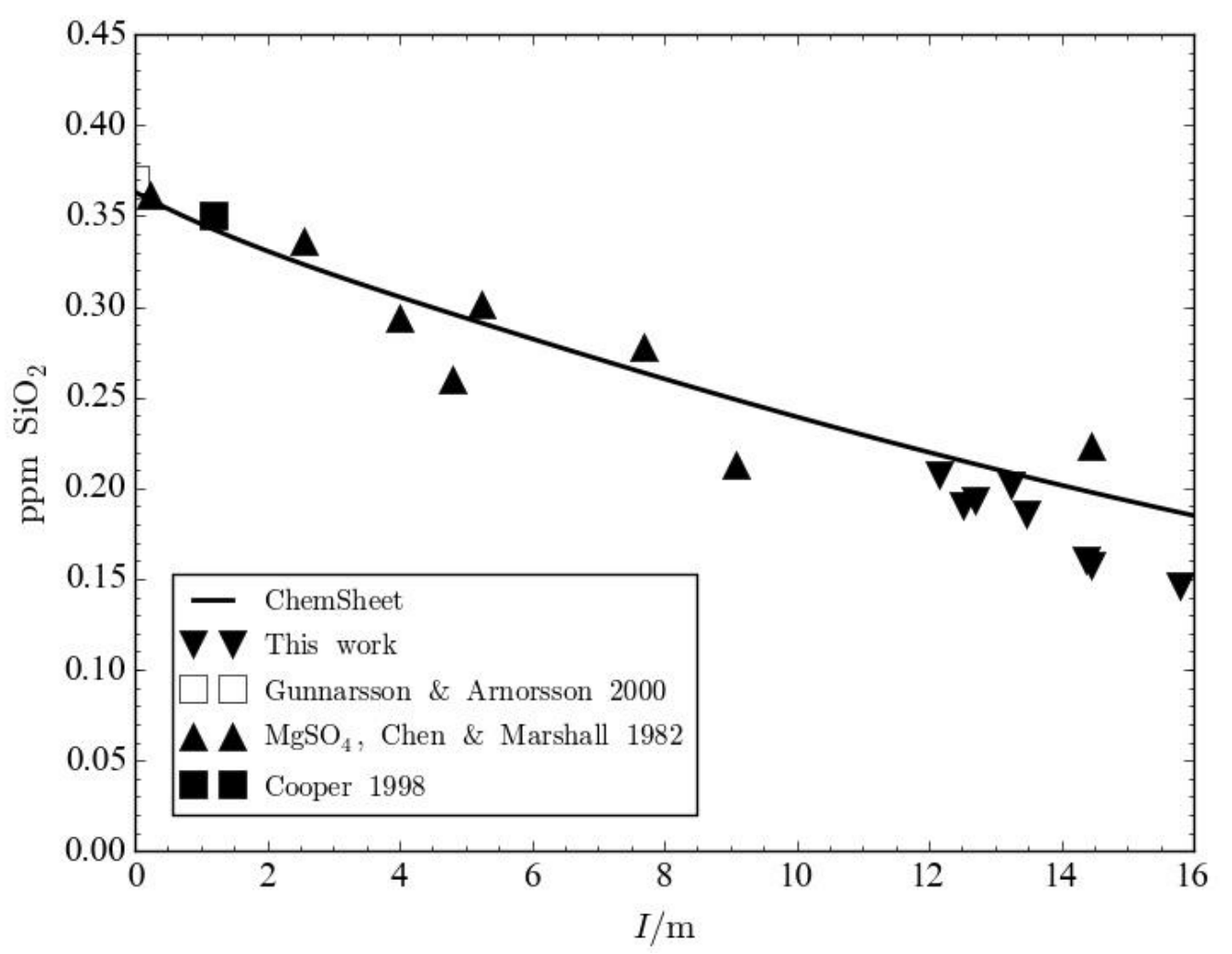


$1 \quad$ Figure 4

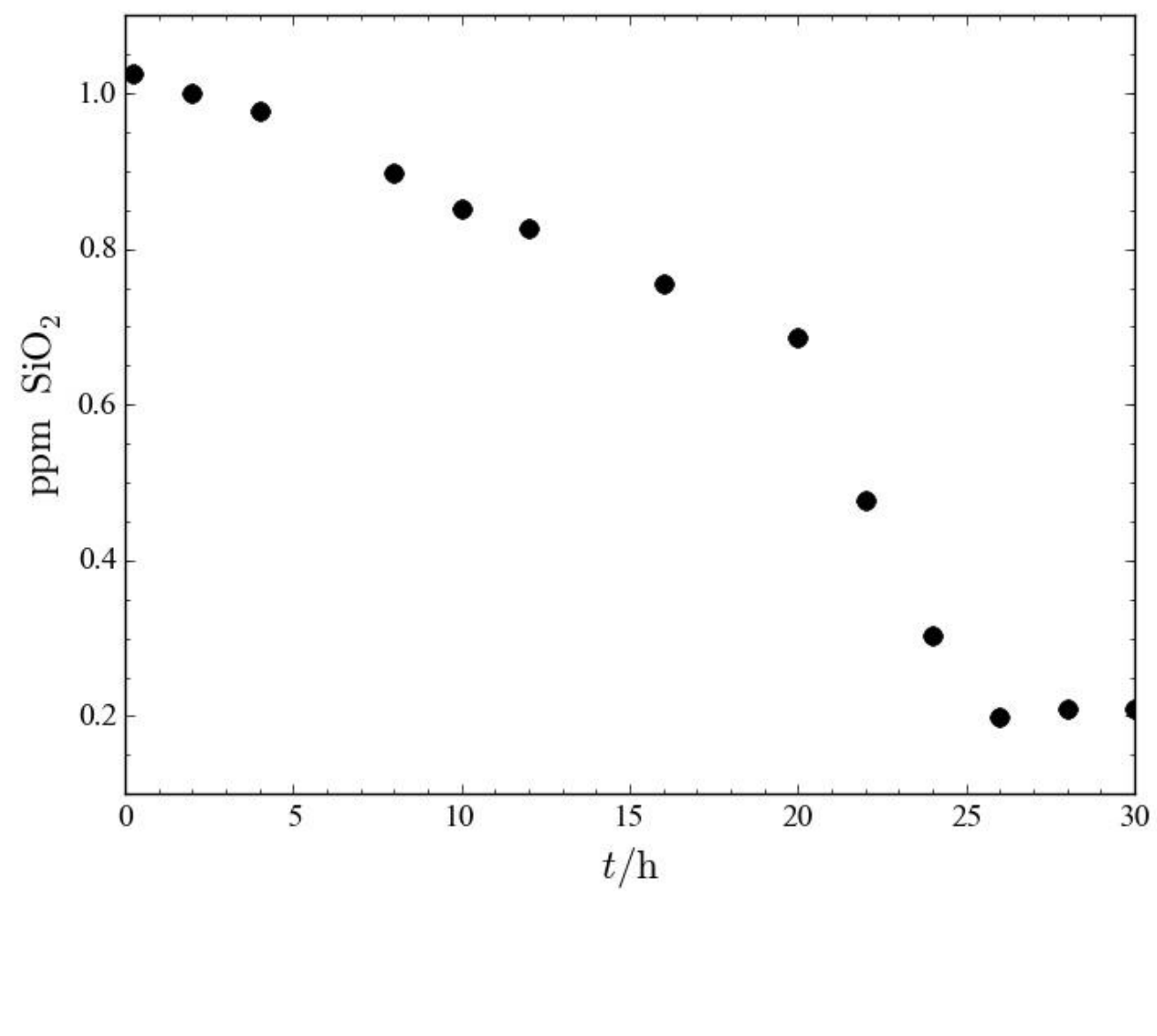


$1 \quad$ Figure 5

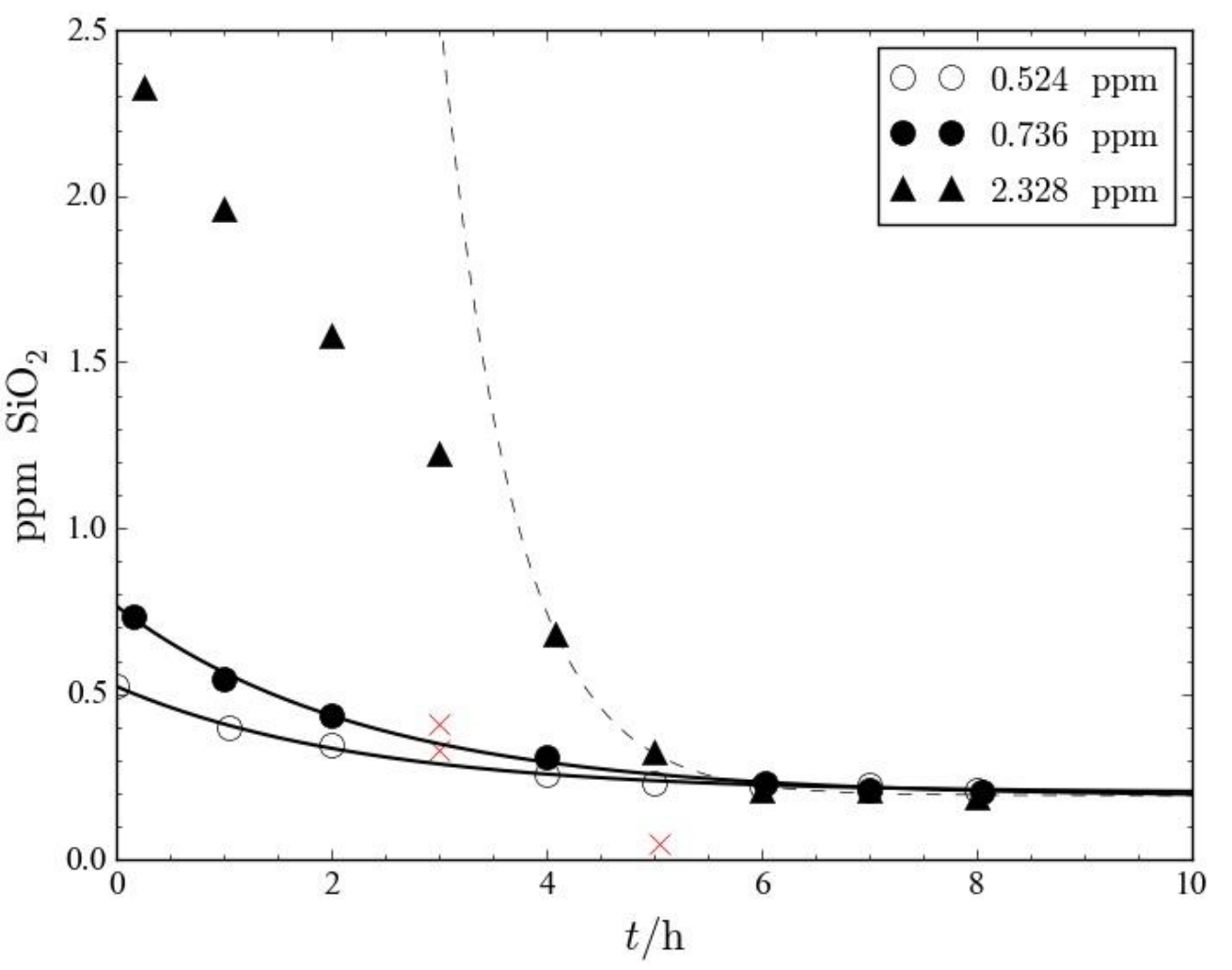

2

3 
$1 \quad$ Figure 6

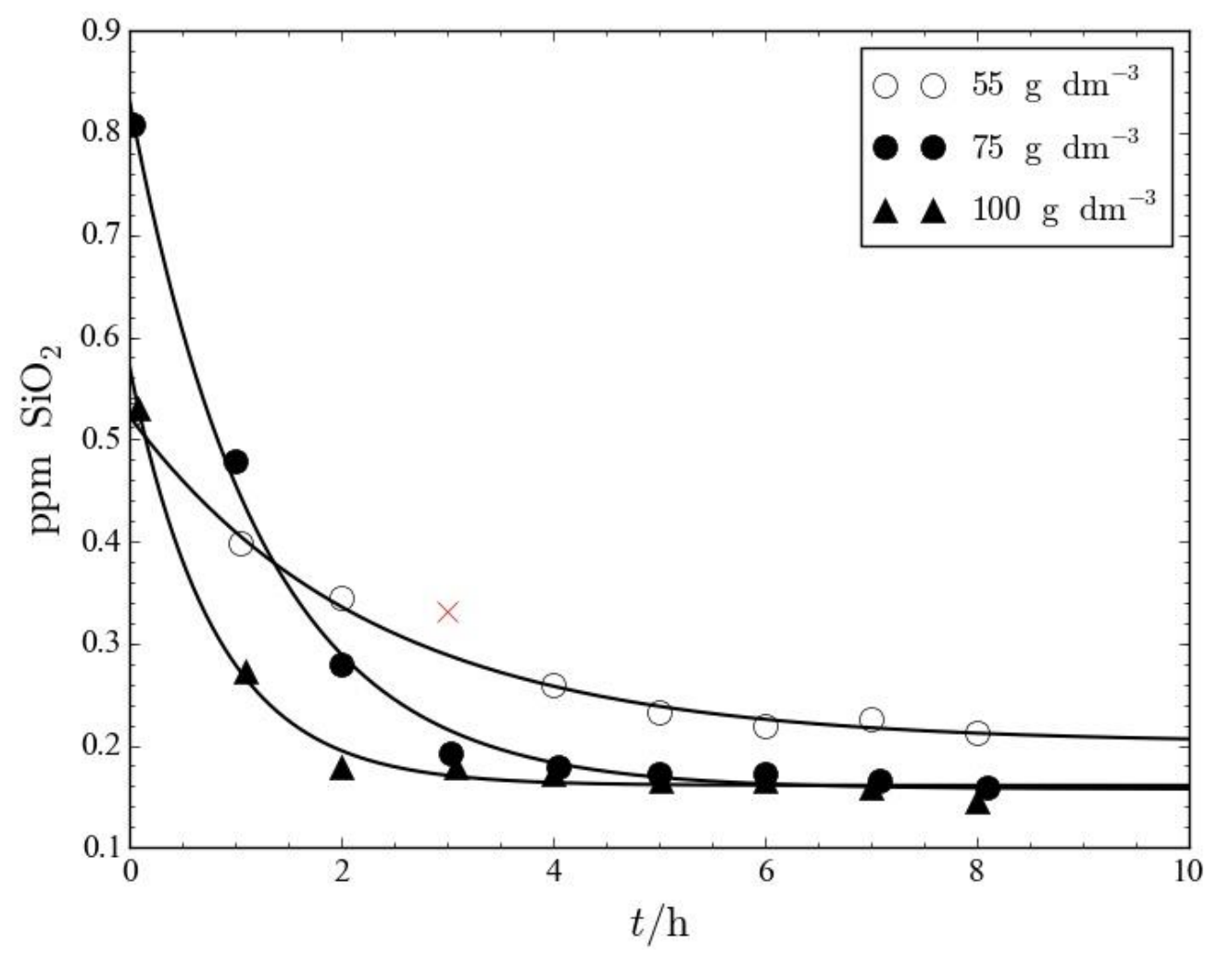




\section{$1 \quad$ Figure 7}

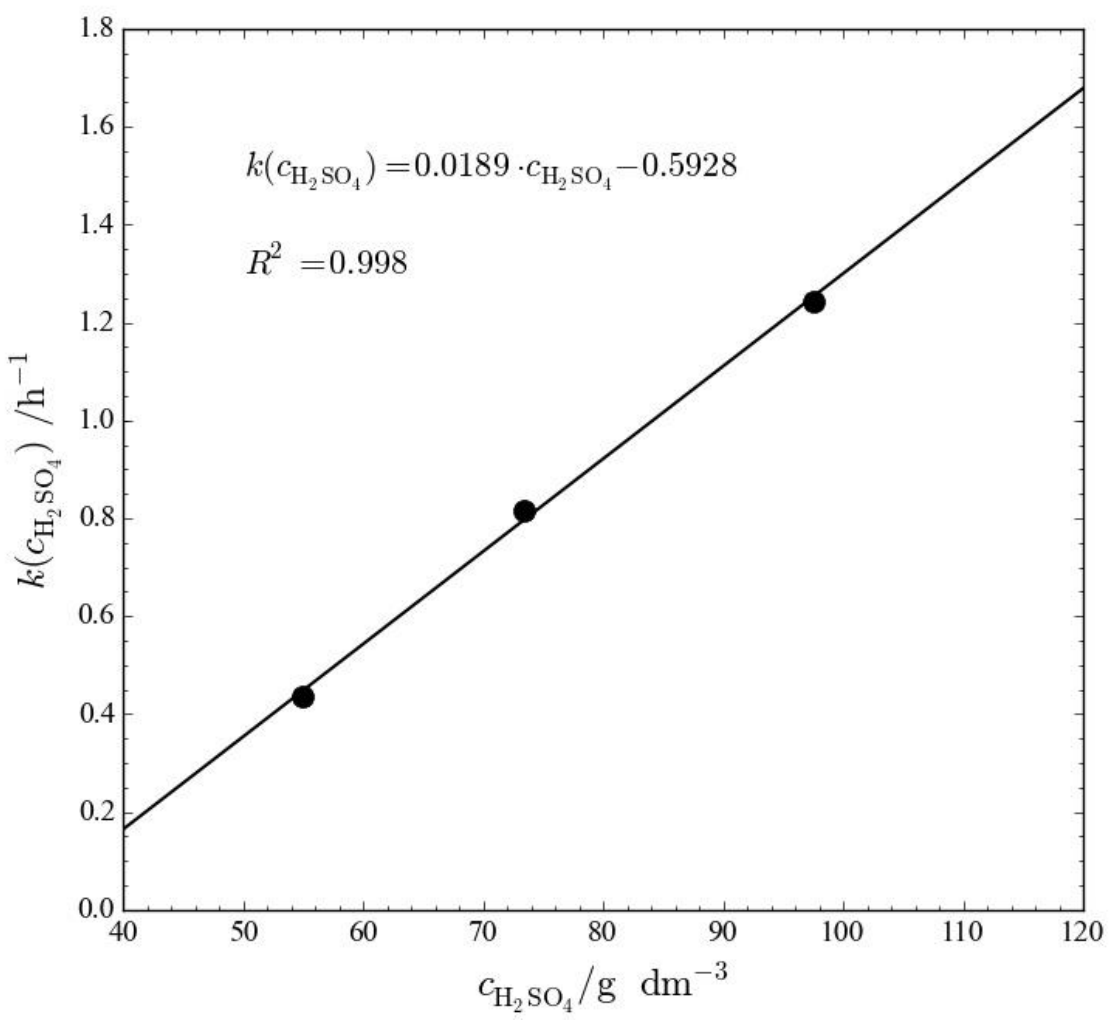


$1 \quad$ Figure 8

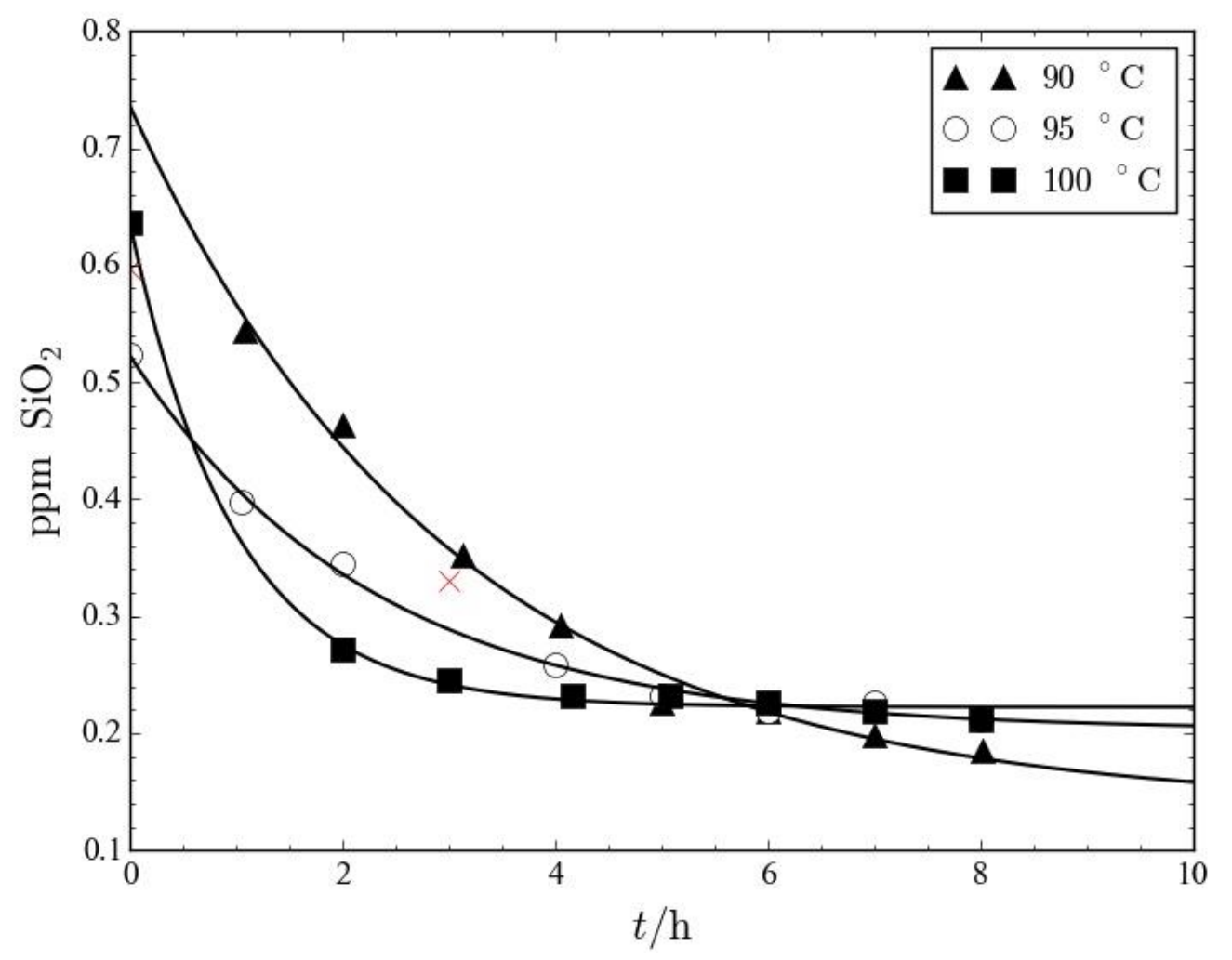

2

3 


\section{$1 \quad$ Figure 9}

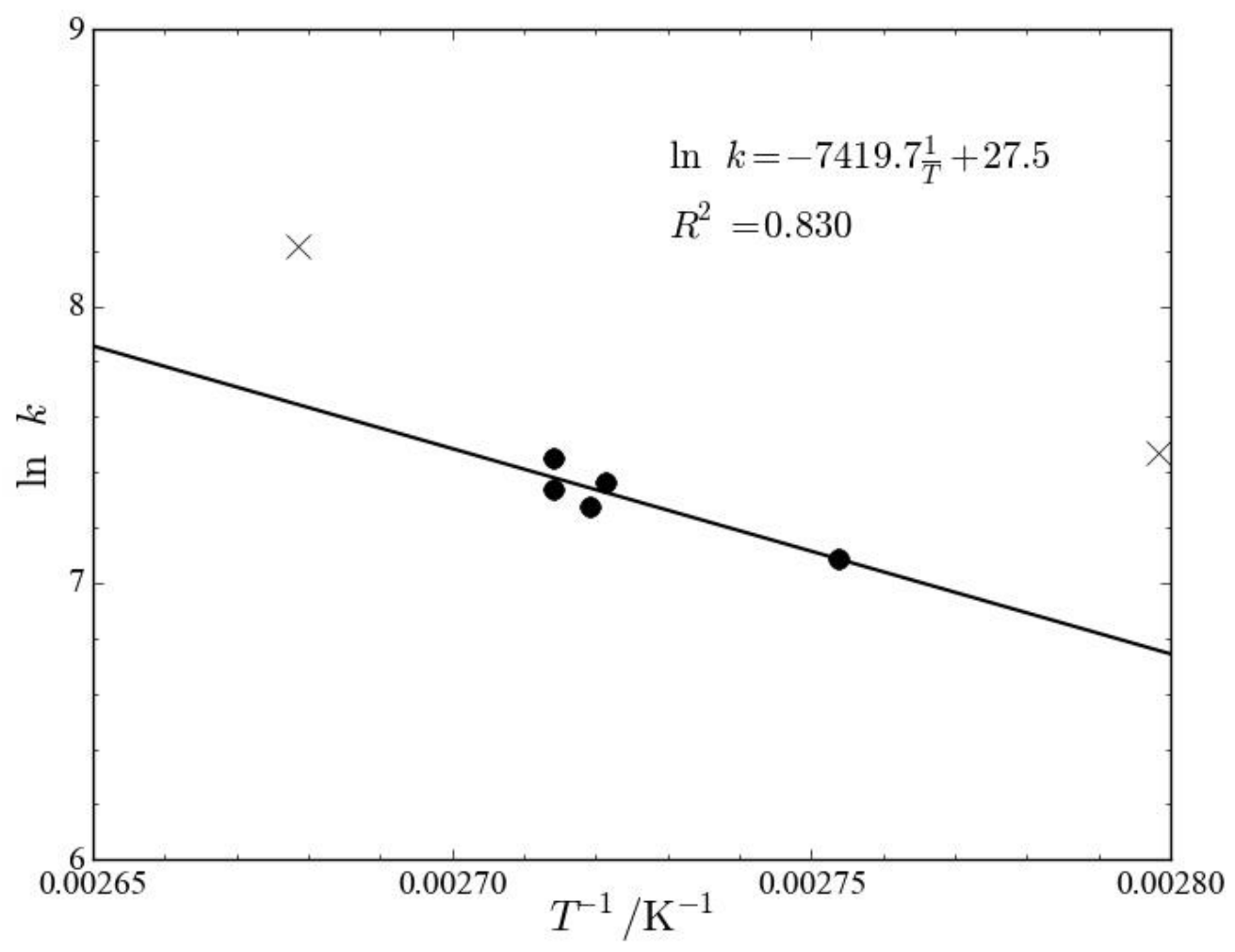

3

4

5

6

7

8 


\section{Graphical abstract}

2

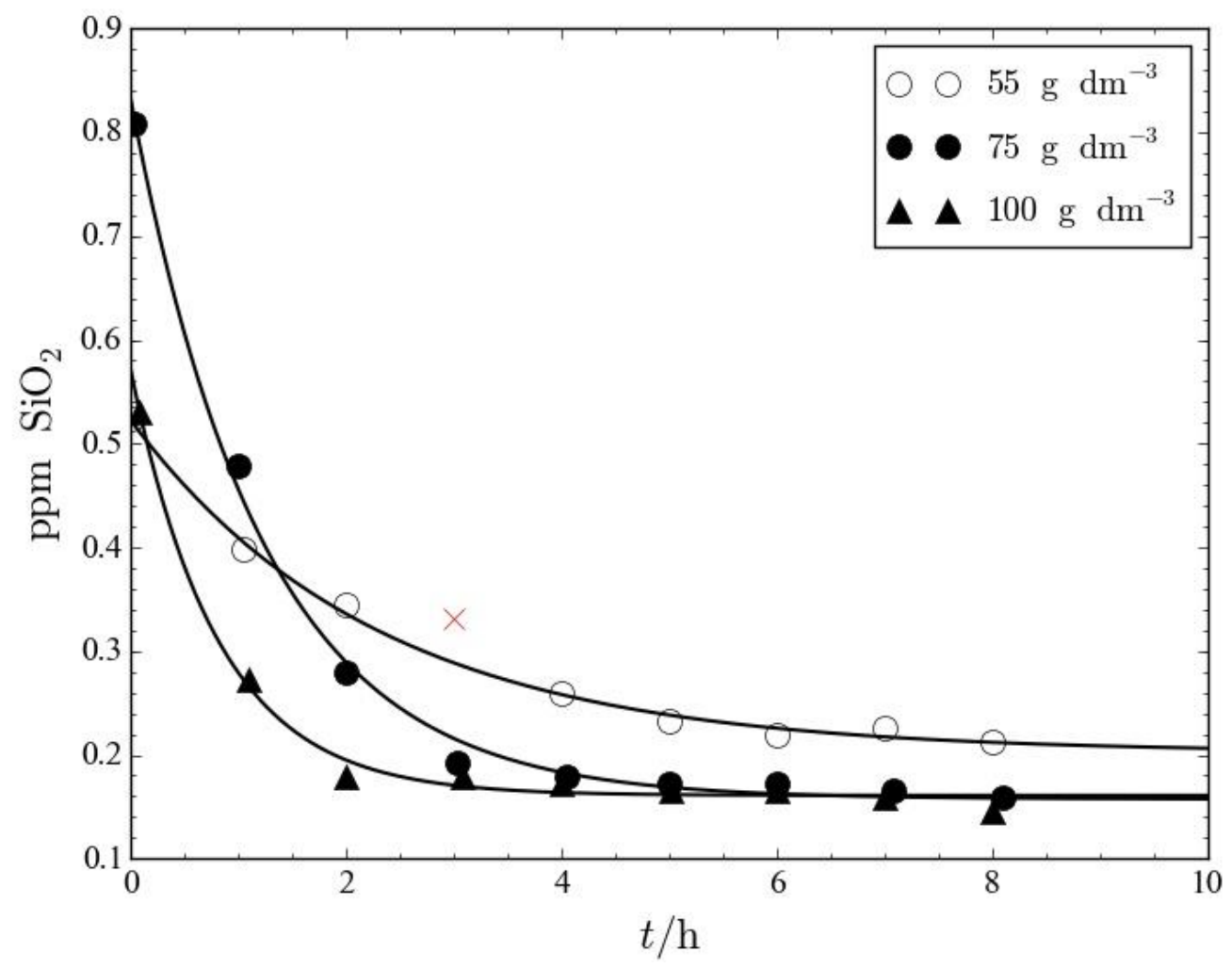

3 